\title{
A Model and Algorithm for Multi-mode and Multi-route Combined Assignment
}

\author{
Wei Zhu \\ School of Naval Architecture, Ocean and Civil Engineering, Shanghai Jiao Tong University \\ 800 Dongchuan Road, Shanghai, P. R. China \\ zhuweimail@163.com
}

\begin{abstract}
Keywords: Multi-mode and Multi-route, Combined Assignment, Comprehensive Link Weight, Transfer Cost

Abstract. With development of economy and society, people's travels in China present the multi-mode and multi-route characteristic more and more normally, and the factors of decision-making become more and more various. A kind of model and algorithm with elastic weight for multi-mode and multi-route combined assignment was developed, as well as the methods for comprehensive link weight calculation and transfer cost calculation based on the characteristics of comprehensive transportation network in China. The proposed model and algorithm proved effective in the passenger flow forecasting for metropolitan rail transit of a southern coastal city in China.
\end{abstract}

\section{Introduction}

As the economy in China keeps on developing, the communication between regions and the communication between inner parts of a region is increasingly close. Cities in the developed areas are even combined as a whole, formation city intensive cluster [1]. To support the development of economy and society in China, transportation develops fast, and presents two great characteristics in supply and demand [2]: Firstly, in terms of demand, travelers' choice of mode is based on more standards, for example accessibility, economic, fast, safety, punctuality, comfort etc., and no longer only focus on accessibility as before; secondly, in terms of supply, there is developed comprehensive transportation network where various vehicles travelers could choose, and convenient transfer between different modes. The above makes region trips have the demand of choices between various modes and various routes, and therefore makes assignment problem of the forecast for passenger volume become complex. In despite of convenience, the traditional methods for transportation demand forecast cannot solve the assignment to the multi-mode and multi-route network because the mode split and the assignment separate from each other [3].

In this paper, a kind of model and algorithm with elastic weight for multi-mode and multi-route combined assignment was developed, as well as the methods for comprehensive link weight calculation and transfer cost calculation based on the characteristics of comprehensive transportation network in China.

\section{Model Illustration}

The activities of travelers in the transportation network should based on a basic hypothesis, that is the total cost including out-of-pocket cost, time cost, and transfer cost i.e. should be minimized. Based on the hypothesis above, the problem of combined assignment with elastic weight for multi-modes and multi-routes transportation network can be formulated as follows:

Min: $Z(x)=\sum_{a} \int_{0}^{x_{a}} T_{a}(\omega) \mathrm{d}(\omega)+\sum_{r} \sum_{s} \sum_{k} f_{k}^{r s} \cdot \eta_{k}^{r s}$

subject to 


$$
\left\{\begin{array}{l}
\sum_{k} f_{k}^{r s}=q_{r s} \\
\sum_{s} \sum_{k} f_{k}^{r s}=P_{r} \\
\sum_{r} \sum_{k} f_{k}^{r s}=P_{s} \\
f_{k}^{r s} \geq 0
\end{array}\right.
$$

$T_{a}(\omega)$ is the unit comprehensive link weight on link $a$, it is the function of the flow $(\omega)$ on link $a$. $f_{k}^{r s}$ is the number of journeys on route NO. $k$ between origin $r$ and destination $s . \delta_{a, k}^{r s}=1$ if link $a$ is on route NO.k between origin $r$ and destination $s$, otherwise $\delta_{a, k}^{r s}=0 . x_{a}$ is the flow volume on link $a$, $x_{a}=\sum_{r} \sum_{s} \sum_{k} f_{k}^{r s} \cdot \delta_{a, k}^{r s} \cdot \eta_{\mathrm{k}}^{\mathrm{rs}}$ is the unit transfer cost on route NO. $k$ between origin $r$ and destination $s$. $q_{r s}$ is the number of journeys between origin $r$ and destination $s . P_{r}$ is the trip production at origin $r$. $P_{s}$ is the trip attraction at destination $s$.

The function of comprehensive link weight on link $a$ is as follows:

$$
T_{a}(\omega)=\left(\xi \cdot \frac{d_{a}}{v_{a}(\omega)} \cdot f_{t a}+\zeta \cdot d_{a} \cdot f_{d a}\right) \cdot C_{1}
$$

$\xi$ is the travel time cost weight. $\zeta$ is the travel out-of-pocket cost weight. $d_{a}$ is the length of link $a$. $v_{a}(\omega)$ is the average speed of the flow on link $a$ when the flow volume on link $a$ is $\omega . f_{t a}$ is the unit time cost on link $a . f_{d a}$ is the unit out-of-pocket cost on link $a . C_{1}$ is the correction parameter. Since railway departments operate according to schedule, $v_{a}(\omega)$ is a constant when link $a$ is a railway. When link $a$ is a highway, the function of $v_{a}(\omega)$ was proposed in Wei Wang's monograph [4].The function of transfer cost is as follows:

$$
\eta=\left[\xi \cdot T \cdot f_{t}+\zeta \cdot f_{d}\right] \cdot C_{2}
$$

$T$ is the transfer time which including the time of getting on and down, the time of getting in and out of stations, and the time of buying tickets. $f_{t}$ is the unit time cost. $f_{d}$ is the unit out-of-pocket cost of transfer. $C_{2}$ is the correction parameter.

In the model above, formula (1) is an objective function, and it will reach a minimum level of total cost when there is an equilibrium transportation network. The item $\sum_{a} \int_{0}^{x_{a}} T_{a}(\omega) \mathrm{d}(\omega)$ is the summation of comprehensive link weight of each route in network and the item $\sum_{r} \sum_{s} \sum_{k} f_{k}^{r s} \cdot \eta_{k}^{r s}$ is the summation of transfer cost of each route in network. Constraint (2) is a conservation constraint that the summation of flow volumes on every route between origin $r$ and destination $s$ must be the number of journeys between origin $r$ and destination $s$. Constraints (3) and (4) are the conservation constraints that the summation of flow volumes on the routes whose origin is $r$ must be the trip production at origin $r$, 
while the summation of flow volumes on the routes whose destination is $s$ must be the trip attraction at destination $s$. Constraint (5) is a non-negative Constraint [3].

\section{Algorithm}

First, we inspect the terms of the objective function. The first term of the objective function contains the integral of a convex increasing function, so the problem is a continuous minimization problem which can be converted into a discrete minimization problem already associated with effective linear programming algorithm. However, the algorithm is complex to be applied to practice.

Since it is impossible for a traveler to make an absolute ideal determination based on accurate calculation of travel cost, he is only able to get the estimation of travel cost. The different between estimation and real cost is a stochastic variable, so the traveler will choose among several routes between a pair of nodes based on probability. Therefore there is another solution to the model above, which is based on logit choice model of route. The algorithm for the logit choice model of route is as follows:

Step 1. Initialisation. Let comprehensive link weights on links be initial values $\left\{T_{a}^{0}\right\}$ which can be the comprehensive link weights when the flows on links are zero. Load the OD matrix to the network based on the logit choice model of route and obtain a set of current flows $\left\{x_{a}^{1}\right\}$. Let $n=1$.

Step 2. Update the set of comprehensive link weights $\left\{T_{a}^{n}\right\}$ with the set of current flows $\left\{x_{a}^{n}\right\}$.

Step 3. Load the OD matrix to the network again based on the logit choice model of route with the set of current comprehensive link weights $\left\{T_{a}^{n}\right\}$ obtained by step 2, and obtain a set of auxiliary flows $\left\{y_{a}^{n}\right\}$.

Step 4. Calculate the current flows as: $x_{a}^{n+1}=x_{a}^{n}+1 / n\left(y_{a}^{n}-x_{a}^{n}\right), \forall a \in A$.

Step 5. If the flows have not changed significantly in two consecutive iterations, stop; otherwise let $n=n+1$, and proceed to step 2 . The condition $\frac{\sqrt{\sum_{a}\left(x_{a}^{n+1}-x_{a}^{n}\right)^{2}}}{\sum_{a} x_{a}^{n}}<\varepsilon(\varepsilon$ is a given value $)$ could be used to decide whether to stop or not.

\section{Case Study}

This paper take the passenger flow forecasting for metropolitan rail transit of a southern coastal city in China for example. The purpose of the project is to forecast the passenger volume in the year 2020. By investigation and analysis, $\xi=0.81, \zeta=0.19$, and $T=20 \mathrm{~min}$ in the year 2020 [5].

Using the computer program based on the proposed model, the results of forecast is that the passenger volume of rail transit system in 2020 is 10263 passenger journeys a day. In addition, the journey OD between stations, average distance of passenger carried and passenger flow diagram can be obtained in order to determinate the scale of the rail transit system, make the operation schedule and evaluate the benefit. Tab. 1 is the passenger volume shares of different modes in metropolitan area, and Tab. 2 is the main targets of the passenger volume forecast.

Table 1 Passenger Volume Shares of Different Modes

\begin{tabular}{|c|c|c|c|c|c|c|c|}
\hline Mode & Car & Bus & Rail transit & Bicycle & Walking & Others & $\begin{array}{l}\text { Total } \\
/(10000 \\
\text { journeys }) \\
\mathrm{d}^{-1}\end{array}$ \\
\hline $\begin{array}{l}\text { Calculation } \\
\text { volume }\end{array}$ & 283.4 & 457.7 & 374.6 & 186.6 & 471.8 & 19.7 & 1793.8 \\
\hline Proportion & $15.8 \%$ & $25.5 \%$ & $20.9 \%$ & $10.4 \%$ & $26.3 \%$ & $1.1 \%$ & $100.00 \%$ \\
\hline
\end{tabular}


Table 2 Main Targets of the Passenger Volume Forecast for Rail Transit

\begin{tabular}{|c|c|c|c|c|c|c|c|c|c|}
\hline \multirow{5}{*}{$\begin{array}{l}\text { Rail } \\
\text { transit }\end{array}$} & $\begin{array}{l}\text { Passenger } \\
\text { volume }\end{array}$ & $\begin{array}{l}\text { Daily } \\
\text { passenger } \\
\text { kilometers }\end{array}$ & $\begin{array}{l}\text { Daily } \\
\text { passenger time }\end{array}$ & $\begin{array}{l}\text { Average } \\
\text { distance of } \\
\text { a journey }\end{array}$ & \multicolumn{2}{|c|}{ average time of a journey } & \multicolumn{2}{|c|}{ Transfer volume } & \multirow{2}{*}{$\begin{array}{l}\text { Transfer } \\
\text { coefficient }\end{array}$} \\
\hline & $\begin{array}{l}10000 \\
\text { journey d }\end{array}$ & $\begin{array}{l}10000 \\
\text { journey } \mathrm{km} \\
\mathrm{d}^{-1}\end{array}$ & $\begin{array}{l}10000 \\
\text { journey·minute } \\
\mathrm{d}^{-1}\end{array}$ & $\begin{array}{l}\mathrm{km} / \\
\text { journey }\end{array}$ & \multicolumn{2}{|c|}{ minute/ journey } & \multicolumn{2}{|c|}{$\begin{array}{l}10000 \text { journey } \\
\mathrm{d}^{-1}\end{array}$} & \\
\hline & 374.55 & 6370.33 & 9555.50 & 17.01 & \multicolumn{2}{|l|}{25.51} & \multicolumn{2}{|l|}{56.18} & 1.08 \\
\hline & \multicolumn{2}{|c|}{ Line length $/ \mathrm{km}$} & \multicolumn{2}{|c|}{$\begin{array}{l}\text { Passenger volume } / 10000 \\
\text { journey }\end{array}$} & \multirow{2}{*}{$\begin{array}{l}\begin{array}{l}\text { Daily } \\
\text { passenger } \\
\text { kilometers }\end{array} \\
10000 \\
\text { journey } \mathrm{km} \\
\mathrm{d}^{-1}\end{array}$} & \multirow{2}{*}{ 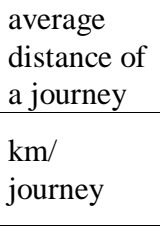 } & \multicolumn{2}{|c|}{$\begin{array}{l}\text { Load intensity } \\
\text { /10000 journey } \\
\mathrm{km}-1\end{array}$} & $\begin{array}{l}\text { average } \\
\text { time of a } \\
\text { journey }\end{array}$ \\
\hline & Core & Whole line & Daily & Peak hour & & & Core & $\begin{array}{l}\text { Whole } \\
\text { line }\end{array}$ & $\begin{array}{l}\text { minute/ } \\
\text { journey }\end{array}$ \\
\hline Line 1 & 47.80 & 47.80 & 132.12 & 15.85 & 2405.91 & 18.21 & 2.76 & 2.76 & 27.32 \\
\hline Line 2 & 55.90 & 67.50 & 80.05 & 9.61 & 1697.06 & 21.20 & 1.54 & 1.19 & 31.80 \\
\hline Line 3 & 42.10 & 42.10 & 58.52 & 7.02 & 828.64 & 14.16 & 1.39 & 1.39 & 21.24 \\
\hline Line 4 & 14.40 & 45.90 & 37.75 & 4.53 & 533.03 & 14.12 & 1.52 & 0.82 & 21.18 \\
\hline Line 5 & 22.20 & 35.00 & 54.85 & 6.58 & 841.40 & 15.34 & 1.85 & 1.57 & 23.01 \\
\hline Line 6 & 17.80 & 17.80 & 11.26 & 1.35 & 64.29 & 5.71 & 0.63 & 0.63 & 8.57 \\
\hline
\end{tabular}

\section{Conclusion}

There are two developments in the proposed combined assignment in this paper:

(1) Comprehensive link weight and transfer cost, which have thought of travel time cost and out-of-pocket cost, are proposed to reflect the multi-mode and multi-route comprehensive transportation network nicely.

(2) The combined model and algorithm proposed in this paper have thought of the travel using more than two transportation modes, that is a certain travel route can consist of more than two transportation modes.

\section{References}

[1] Ren Z.Y. Views on City and City Planning. Beijing; China Electricity Power Press, 2005.

[2] Zhu W. A Model of Demand Forecasting for Park and Ride System in Big City. Proceedings of the 2nd International Conference on Transportation Engineering. Chengdu, China, 2009.

[3] Shao C.F. Traffic Planning Theory. Beijing; China Railway Press, 2004.

[4] Wang W. Methods for Planning, Construction and Management of Highway Networks. Beijing; Science Press, 2001.

[5] Xu R.H., Teng J., Zhu W., et al. Research on the Rail Transit System Planning for Quanzhou Metropolitan. Tongji University, 2010. 